\begin{tabular}{cccc} 
Available online at www.sinjas.journals.ekb.eg & \\
\hline SCREENED BY SINAI Journal of Applied Sciences
\end{tabular}

\title{
AN ECONOMIC STUDY FOR SHEEP FATTING IN ISMAILIA GOVERNORATE
}

\author{
AbdulFattah N. Eshtewy ${ }^{*}$, R.I.M. Radwan ${ }^{1}$ and R.M. Hefny ${ }^{1}$ \\ 1. Environ. Studies Inst., Arish Univ., Egypt. \\ 2. Dept. Econ. and Rural Develop., Fac. Environ. Agric. Sci., Arish Univ., Egypt.
}

\begin{tabular}{l} 
ARTICLE INFO \\
\hline Article history: \\
Received: $28 / 08 / 2021$ \\
Revised: $22 / 09 / 2021$ \\
Accepted: $11 / 10 / 2021$ \\
Available online: $11 / 10 / 2021$ \\
\hline Keywords: \\
Economic Study, \\
sheep, \\
Ismailia Governorate
\end{tabular}

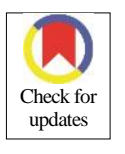

\begin{abstract}
The small ruminants of sheep and goats in Ismailia Governorate are one of the most important sources of animal production, the problem of study is the deficit of production capacity of red meat, estimated at about 791 thousand tons, to meet the needs of consumption which, estimated at about 1167 thousand tons, that resulted in a meat gap estimated at about 376 thousand tons epically with the continuous increase in population. The research aims to study the productive and economic efficiency of sheep fattening. The study relied on both descriptive and quantitative economic analysis methods. The results showed that the average fixed costs amounted to about L.E. 552.2 per head, with a relative importance of about $18.83 \%$. General average of variable costs amounted to about L.E. 2,380.8 per head, with a relative importance of about $81.17 \%$ of the total The average total costs amounting to about L.E. 29.33 per head, when studying the profit margins, the general average of total head income was about L.E. 3506.5, the average net return amounted to about L.E. 573.5 L.E. of the average return above the variable costs was about 1125.7 L.E, the average of value added, was L.E. 989.3. The average return on costs was about 1.19 , the average return on the invested found was about $19.5 \%$, and the average profit margin was about $16.3 \%$. The study also recommends the need to develop natural pastures and pay attention to providing good breeds.
\end{abstract}

$$
\begin{aligned}
& \text { جنيهاً للكيلوجرام وزن قائم عام 2019، بنسبة زيادة }
\end{aligned}
$$

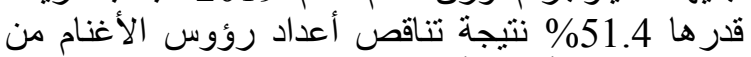

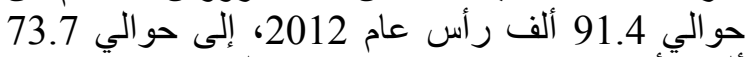

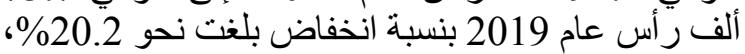

$$
\begin{aligned}
& \text { مما ترتب عليه انخفاض نصيب الفيبة الفرد من البروتين } \\
& \text { الحيو اني، خلال تلك الفترة. }
\end{aligned}
$$

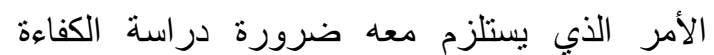

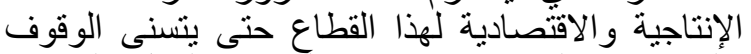

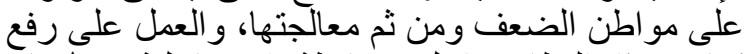

$$
\begin{aligned}
& \text { كفاءة هذا القطاع داخل محافظة الإسماعلية (سليمان }
\end{aligned}
$$

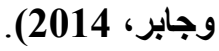

$$
\begin{aligned}
& \text { أهداف الدراسة وابر، } \\
& \text { يستهدف البحث بصفة عامة إلقاء الضوء الإه على الكفاءة }
\end{aligned}
$$

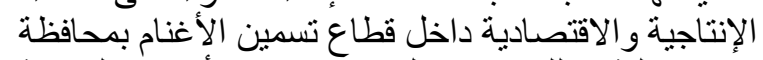

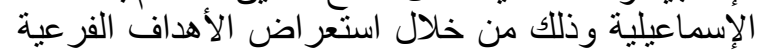

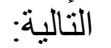

\section{مقدمة}

$$
\begin{aligned}
& \text { تعتبر المجترات الصغغيرة من الأغنام والماعز في }
\end{aligned}
$$

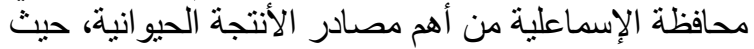

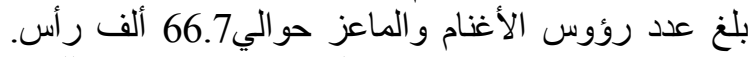

$$
\begin{aligned}
& \text { تساهم في إنتاج ما يقرب من حون الي } 3515.1 \text { طن طن من اللحوم } \\
& \text { وزن قائم، تقدر قيمتها النقدية بحوالي } 202.4 \text { مليون جني الئيه } \\
& \text { هذا وقد بلغت القيمة المضافة لقطاع تسمين الأغنام حوالي في }
\end{aligned}
$$

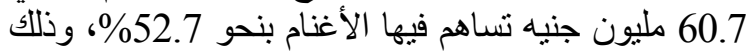

$$
\begin{aligned}
& \text { خلال عام (2015 -2019). } \\
& \text { مشكبة البحث } \\
& \text { في ظل التزايد المستمر في أعداد السكان بمحافظة }
\end{aligned}
$$

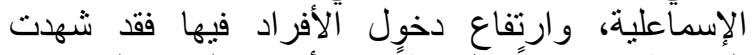

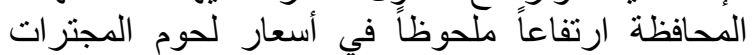

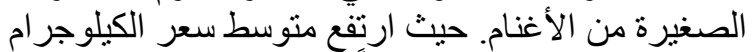

$$
\begin{aligned}
& \text { وزن قائم من حوالي } 35 \text { جنيهاً عام الأمن } 2012 \text { إلى حو الي } 53
\end{aligned}
$$

\footnotetext{
* Corresponding author: E-mail address: abdelfattaheshtawy70@ gmail.com https://doi.org/10.21608/sinjas.2021.93042.1044

(C) 2021 SINAI Journal of Applied Sciences. Published by Fac. Environ. Agric. Sci., Arish Univ. All rights reserved.
} 
وعن الفئة الحبازية الثالثة فقد بلغ عدد رؤوس الأغنام

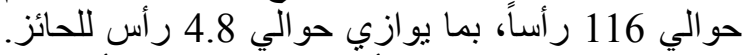

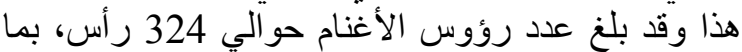

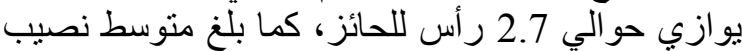
الحائز من الأَغنام حوالي (2-3) رأس.

هذا وقد ارتفعت الأهمية النسبية لعدد مزارع ارع الإع الفئة

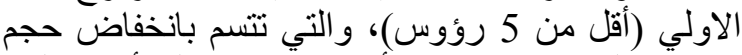

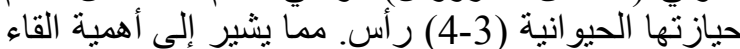

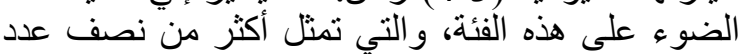
مز مزارع التسمين داخل العينة.

\section{معالم اداء نظم تسمين الأغنام بعينة الاراسة}

يوضح جدول 2 معالم أداء نظم تسمين الأغنام داخل مختلف الفئات الحيازية بعينة الدراسة في لئلة محافظة الإسماعلية خلال موسم تسمين 2020 و ونها ينبين أن:

$$
\text { الوزن عند الثراء }
$$

أكدت النتائج أن وزن الرأس عند الثراء قاء لد بلغ أدنى

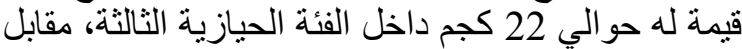
حو الي 27 كجم للر أس داخل الفئة الحيازية الأولي. وقد بلغ المتوسط العام لوزن الرأس عند الثراء

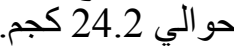

\section{الوزن عند البيع (الوزن التسويقي)}

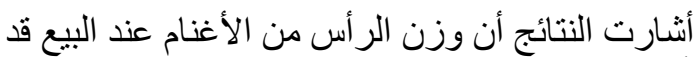

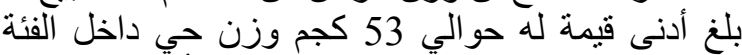

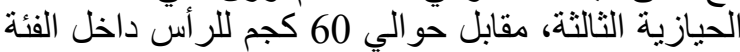

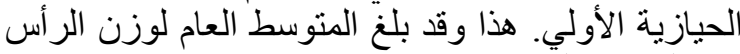

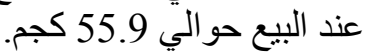

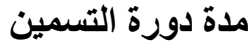

تشير الأرقام أن مدة دورة التسمين للأغنام قد بلغت الته

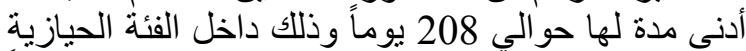
الثانية، في حين بلتغت أقصى مدة لهاني لها حوالي 215 يوماً. وذلك داخل الفئة الحيازية الأولي. هذا وقد بلغ متوسط مدة الدورة بقطاع تسمين الأغنام حو الي 212.5 يوماً.

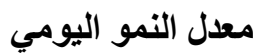

أكدت النتائج أن معدل النمو اليومي للر أس من الأغنام

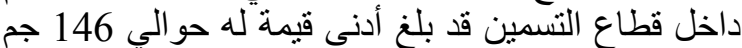

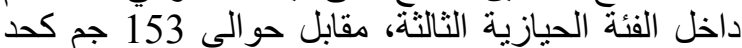

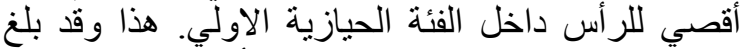
المتوسط العام لمعدل النمو اليومي للرأس حوالي الي 149.2

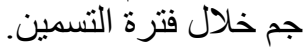

مما سبق تبين ارتفاع الكفاءة التحويلية لمز ار ع تسمين

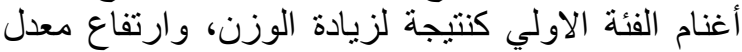

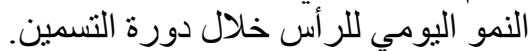

1- استعر اض كيفية اختيار عينة الدر اسة وعرض المؤشرات العامة المرتبطة بقطاع تسمين الأغنام داخل العينة. 2-دراسة الأهية النسبية لبنود هيكل التكاليف داخل نشاط تسمين الأغنام بعينه الدراسة.

3- دراسة كفاءة أداء وتقييم قطاع تسمين الأغنام داخل

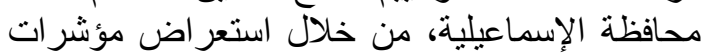

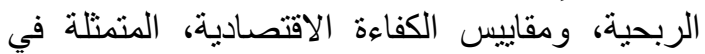
عائد الجنيه المستثمر، هامش ربح الإنه المنتج، الربحية الاقتصادية، و المقياس العام للكفاءة الاقتصادية.

\section{الأسلوب البحثي ومصادر جمع البيانات}

اعتمدت الدراسة في تحقيق أهدافها على أسلوبي

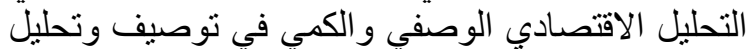
المتغيرات الاقتصادية المرتبطة بالدراسة، ولقائ القد استخدم العديد من أساليب التحليل الإحصائي، مثل الألئيل الأساليب

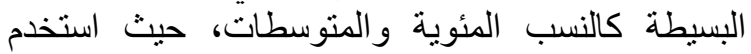
نوعين من البيانات، أولهما البيانات الثانوية المنشورة الئنة

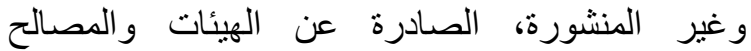

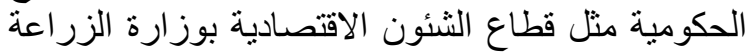

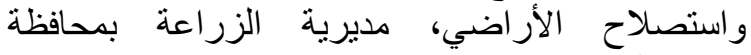

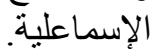

بالإضافة إلى بعض الدراسات العلمية ذات الصلة

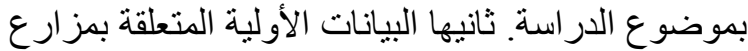

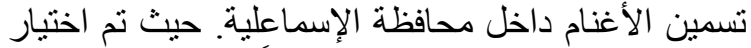

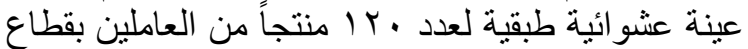

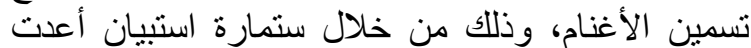
خصيصاً لهؤ لاء المنتجين عن طريق المقابلة الثخصية.

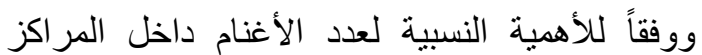

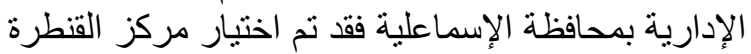

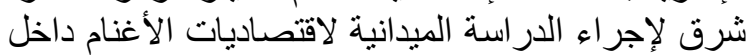

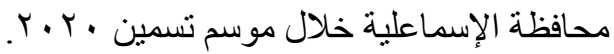

\section{النتائج ومناقشتها}

اختيار عينة الدراسة وعرض المؤشرات العامة المرتبطة بقطاع تسمين الأغنام داخل العينة التوزيع الصنفي لحجم القطيع من الأغنام

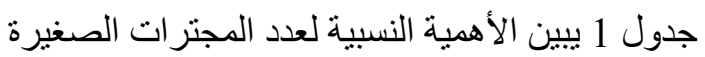

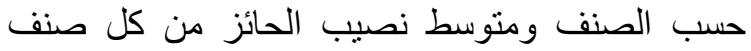
داخل مختلف الفئات الحيازية بعينة الدراسة في محافظة

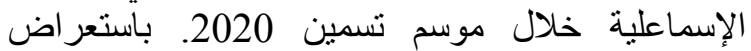
الأرقام الواردة بالجدول يتبين أن عدد رؤوس الأوس الأغنام

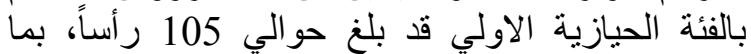
يو ازي حو الي 1.6 رأس للحائز ، اما بالنسبة للفئة الحيازية روالية

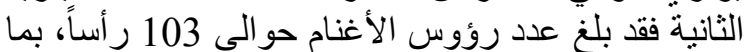
يو ازي حو الي 3.2 رأس للحائز. 
جدول 1. الأهمية النسبية لعدد المجترات الصغيرة حسب الصنف ومتوسط نصيب الحائز من كل صنف داخل مختلف الفئات الحيازية بعينة الاراسة في محافظة الإسماعلية خلال موسم تسمين 2020

\begin{tabular}{|c|c|c|c|}
\hline متوسط نصيب الحائز & $(\%)$ & عدد الأغنام & الفئات الحيازية \\
\hline 1.64 & 32.4 & 105 & الفئة الأولي (أقلّل من 5 رؤوس) \\
\hline 3.22 & 31.8 & 103 & الفئة الثانية (5-10 رؤوس) \\
\hline 4.83 & 35.8 & 116 & الفئة الثالثة (10رؤوس فأكثر) \\
\hline 2.70 & 100 & 324 & جملة العينة \\
\hline
\end{tabular}

المصدر: جمعت وحسبت من استمارات الاستيان الخاصة بالدراسة الميدانية.

جدول 2. معالم أداء نظم تسمين الأغنام داخل مختلف الفئات الحيازية بعينة الدراسة في محافظة الإسماعلية خلال موسم تسمين 2020

\begin{tabular}{|c|c|c|c|c|c|}
\hline $\begin{array}{c}\text { معدل اللنمو } \\
\text { اليومي }(ج م)\end{array}$ & 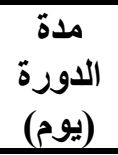 & الزيادة & وزن اللرأس & وزن الرأس عند & الفئات الحيازية \\
\hline 153 & 215 & 33 & 60 & 27 & الفئة الأولي (أقلّ من 5 رؤوس) \\
\hline 149 & 208 & 31 & 55 & 24 & الفئة الثانية (5-10 رؤوس) \\
\hline 146 & 212 & 31 & 53 & 22 & الفئة الثالثة (10رؤوس فأكثر) \\
\hline 149.2 & 212.5 & 31.7 & 55.9 & 24.2 & المتوسط \\
\hline
\end{tabular}

المصدر: جمعت وحسبت من استمار ات الاستبيان الخاصة بالار اسة الميدانية.

هذا وقد بلغ الاجمالي العام لتكلفة الرأس حوالي بلي

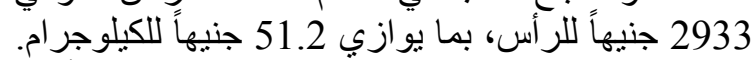

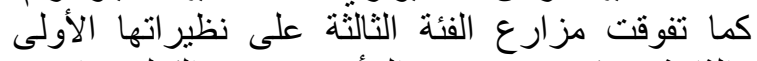

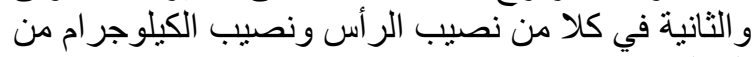
التكاليف.

الهوامش الربحية داخل قطاع تسمين الأغنام داخل عينة الدراسة

يوضح جدول 4 الهو امش الربحية داخل قطاع تسمين

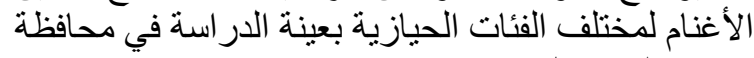
الإسماعلية خلال موسم تسمين2020 الإنة ومنه ينتين:

$$
\text { الاير ادات الكلية }
$$

جملة الإير ادات الكلية للر أس من أغنام التسمين قد بلغت

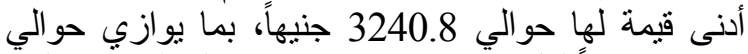

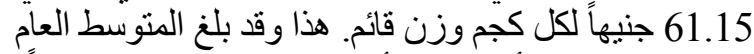

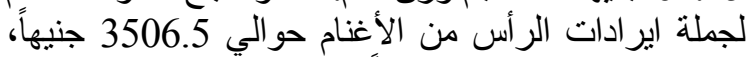

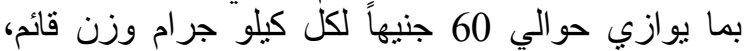

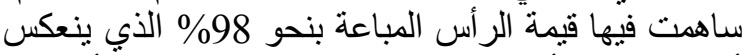
أثره في زيادة أرباح القائمين داخل نشاط تسمين الُّأغنام.
الأهمية النسبية لبنود هيكل التكاليف داخل نثاط تسمين الأغنام بعينه الاراسة لألة هيكة

يوضح جدول 3 الأهمية النسبية لبنود هيكل التكاليف

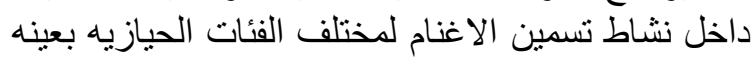

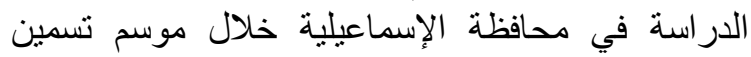
2020 ومنه ويتبين أن إجمالي التكاليف الثابتة للر أس من الإن

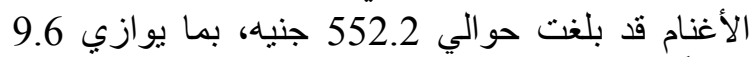
جنيهاً للكيلو جر ام، تمثل نحو 18.8\% من بلف جملة التكاليف،

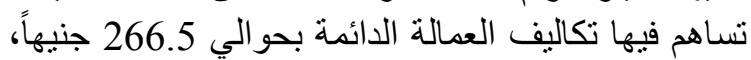
بما يوازي 4.6 كيلو جرام. كما بلغت إجمالي التكاليف لئي

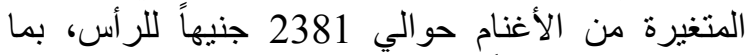
يوازي 41.6 جنيهاً للكيلو جرام تمثل نحو جملة التكاليف، تساهم فيها قيمة رأس التسمين بحوالي تلئ 1253.5 جنيهاً للر أس، بما يوازي في في 21.9 للكيلو جر ام تمثل

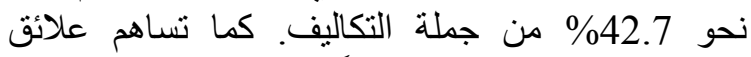

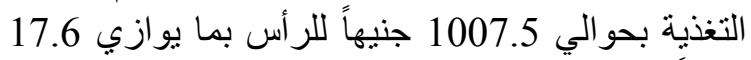
جنيهاً للكيلو جرام تمثل نحو 34.35\% من جملة 
جدول 3. الأهمية النسبية لبنود هيكل التكاليف داخل نثاط تسمين الأغنام لمختلف الفئات الحيازية بعينة الدراسة داخل محافظة الإسماعيلية خلال موسم تسمين 2020

\begin{tabular}{|c|c|c|c|c|c|c|c|c|c|}
\hline \multicolumn{3}{|c|}{ إجمالي العينة } & \multicolumn{2}{|c|}{ 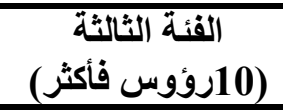 } & \multicolumn{2}{|c|}{ 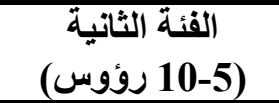 } & \multicolumn{2}{|c|}{ (أقل من 5 روؤوسلى الأولى } & \multirow[b]{2}{*}{ بنود هيكل التكاليف } \\
\hline$(\%)$ & م. نصيب & م. نصيب أسب & م. نصيب & م. نصيب & م. نصيب & م. نصيب & 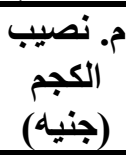 & م. نصيب & \\
\hline & & & & & & & & & التكاليف الثابتة \\
\hline 9.09 & 4.65 & 266.5 & 3.86 & 204.8 & 4.34 & 239.1 & 5.06 & 303.4 & عمالة دائمة \\
\hline 5.09 & 2.61 & 149.3 & 2.30 & 122.1 & 2.57 & 141.6 & 2.72 & 163.2 & عمالة عائلية \\
\hline 2.03 & 1.04 & 59.5 & 1.24 & 65.5 & 1.06 & 58.5 & 0.96 & 57.8 & الفائدة على رأس المال \\
\hline 1.04 & 0.53 & 30.5 & 0.39 & 20.8 & 0.46 & 25.4 & 0.61 & 36.7 & الاهلاك للحظيرة \\
\hline 0.99 & 0.50 & 28.9 & 0.41 & 21.7 & 0.45 & 24.9 & 0.56 & 33.6 & تكاليف مقابل الايجار \\
\hline 0.60 & 0.31 & 17.5 & 0.25 & 13.2 & 0.28 & 15.6 & 0.34 & 20.1 & الاهلاك للأدوات والمعدات \\
\hline 18.83 & 9.64 & 552.2 & 8.45 & 448.1 & 9.17 & 505.1 & 10.25 & 614.8 & جملة \\
\hline 42.74 & 21.88 & 1253.5 & 20.94 & 1109.7 & 21.87 & 1205.2 & 22.20 & 1332.1 & قيمة رأس التسمين التئيرة \\
\hline 25.76 & 13.18 & 755.5 & 11.70 & 620.1 & 12.79 & 704.6 & 13.86 & 831.8 & أعلاف مركزة \\
\hline 5.84 & 2.99 & 171.2 & 2.40 & 127.4 & 2.76 & 152.3 & 3.28 & 197.0 & أعلاف جافة \\
\hline 2.75 & 1.41 & 80.8 & 1.92 & 101.9 & 1.73 & 95.2 & 1.10 & 65.7 & أعلاف خضراء \\
\hline 34.35 & 17.58 & 1007.5 & 16.03 & 849.4 & 17.28 & 952.1 & 18.24 & 1094.5 & جملة \\
\hline 2.56 & 1.31 & 75.0 & 1.18 & 62.7 & 1.28 & 70.4 & 1.37 & 81.9 & إثراف بيطري وادوية \\
\hline 0.63 & 0.32 & 18.6 & 0.28 & 15.1 & 0.33 & 18.0 & 0.34 & 20.2 & فرشة \\
\hline 0.46 & 0.23 & 13.4 & 0.19 & 10.1 & 0.24 & 13.1 & 0.25 & 14.8 & مياه و إنارة \\
\hline 0.44 & 0.22 & 12.8 & 0.22 & 11.7 & 0.22 & 12.2 & 0.23 & 13.5 & نقل وانتقالات عامة \\
\hline 81.17 & 41.55 & 2380.8 & 38.84 & 2058.7 & 41.20 & 2270 & 42.62 & 2557 & جملة \\
\hline 100.0 & 51.19 & 2933 & 47.30 & 2506.8 & 50.36 & 2775.1 & 52.86 & 3171.8 & الإجمالي العام \\
\hline & & 57.3 & & 53 & & 55.1 & & 60 & وزن رأس كجم \\
\hline
\end{tabular}


Eshtewy, et al. | SINAI Journal of Applied Sciences 10 (2) 2021 229-236

جدول 4. الهوامش الربحية داخل قطاع تسمين الأغنام لمختلف الفئات الحيازية بعينة الدراسة في محافظة الإسماعيلية

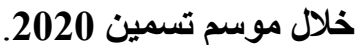

\begin{tabular}{|c|c|c|c|c|c|c|c|c|}
\hline \multicolumn{2}{|c|}{ المتوسط العام لجملة العينة } & \multicolumn{2}{|c|}{ 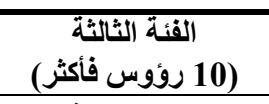 } & \multicolumn{2}{|c|}{ 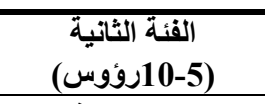 } & \multicolumn{2}{|c|}{ أقل من 5 روؤوسي } & \multirow[b]{2}{*}{ البيان البيان } \\
\hline الكجم قائم & مُ ألرأسيب & م. قالكجم & م. نصيب & م. ماكجميب & م. نصيب & م. قالكجميب & م. نالريب & \\
\hline & & & & & & & & الهوامش الربحية \\
\hline 60.0 & 3438 & 60.0 & 3180 & 60.0 & 3306 & 60.0 & 3600 & إيرادات الرأس المباعة (1) \\
\hline 1.2 & 68.5 & 1.15 & 60.8 & 1.14 & 62.7 & 1.24 & 74.3 & إيراد السماد (2) \\
\hline 61.2 & 3506.5 & 61.15 & 3240.8 & 61.14 & 3368.7 & 61.24 & 3674.3 & جملة الإيرادات (3) \\
\hline 51.19 & 2933.0 & 47.30 & 2506.8 & 50.37 & 2775.1 & 52.86 & 3171.8 & التكاليف الكلية (4) \\
\hline 10.01 & 573.5 & 13.85 & 734.0 & 10.77 & 593.6 & 8.38 & 502.5 & صافي العائد (5) \\
\hline 41.55 & 2380.8 & 38.84 & 2058.7 & 41.20 & 2270.0 & 42.62 & 2557.0 & التكاليف المتغيرة (6) \\
\hline 49.99 & 2864.5 & 46.15 & 2446.0 & 49.23 & 2712.4 & 51.62 & 3097.5 & التكاليف المعدلة (7) \\
\hline 19.65 & 1125.7 & 22.31 & 1182.1 & 19.94 & 1098.7 & 18.62 & 1117.3 & لعائد فوق التكاليف المتغيرة(8) \\
\hline 17.26 & 989.3 & 20.20 & 1060.9 & 17.98 & 974.3 & 16.15 & 969.1 & القيمة المضافة (9) \\
\hline
\end{tabular}

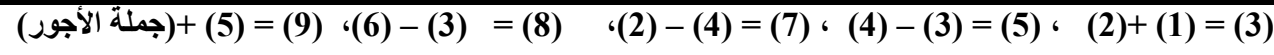

المصدر: جُمعت وحُسبت من واقع استمارات الاستبيان الخاصة بالدر اسة الميدانية.

مقاييس الكفاءة الاقتصادية لقطاع تسمين الأغنام

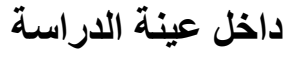

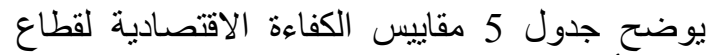

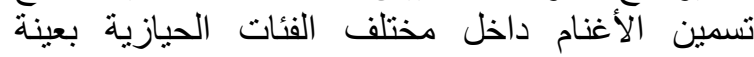
الدراسة في محافظة شمال سيناء خلال موسم تسمين 2020 وفيه يتبين:

\section{نسبة الإيراد للتكاليف:}

بلغ منوسط عام نسبة العائد للتكاليف نحو 1.19.

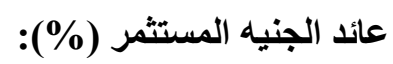

بلغ متوسط عام عائد الجنيه المستثر (\%) نحو 19.5\%

$$
\text { هامش ربح المنتج (\%) }
$$

بلغ منوسط عام هامش ربح المنتج (\%) نحو 16.3

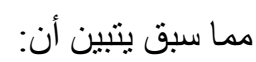

1- أن قطاع تسمين الأغنام داخل الفئة الحيازية الثالثة (10)

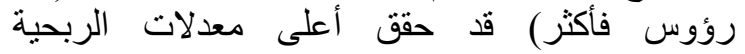

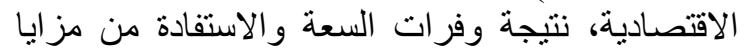
الانتاج الوفير، وهذا ما يتعلق مع النظة النظرية الاقتصادية، في حين حققت مزارع الإنئة الأولى أقل معدلات الرئل الربحية

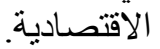

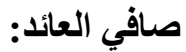

بلغ المتوسط العام لصافي عائد الر أس حوالي 573.5 جنيهاً، بما يوازي حوالي 10 جنيهاً لكل كجم وزن قالئل قائر، وذللك خلال موسم تسمين 2020.

\section{العائد فوق التكاليف المتغيرة:}

لقد بلغ المتوسط العام للعائد فوق التكاليف المتغيرة

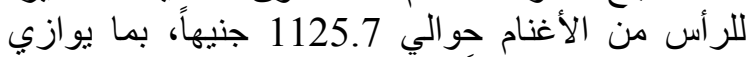
حوالي 19.65 جنيهاً لكل كجم وزن فائم، وذللك خلال موسم تسمين 2020.

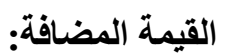
قد بلغ المنوسط العام لنصيب رأس الأغنام من القيمة

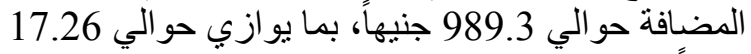
جنيهاً لكل كجم وزن قائم، وذلك خلال موسم تسمين .2020

مما سبق يتبين أن مزارع الفئة الحيازية الثالثة (10)

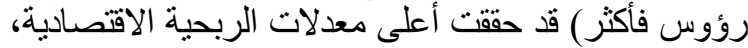
في حين حققت مز ارع الفئة الحيازية الأولى (أقل من 5 رؤوس) أقل معدلات الربحية الاقتصادية.

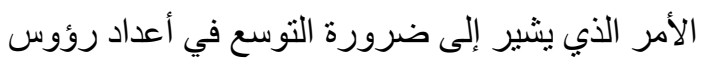
التسمين بمز ارع القطاع داخل محافظة الإسماعلية، الأمر. 
جدول 5. مقاييس الكفاءة الاقتصادية بقطاع تسمين داخل مختلف الفئات الحيازية بعينة الاراسة في محافظة الإسماعيلية خلال موسم تسمين الاعة 2020

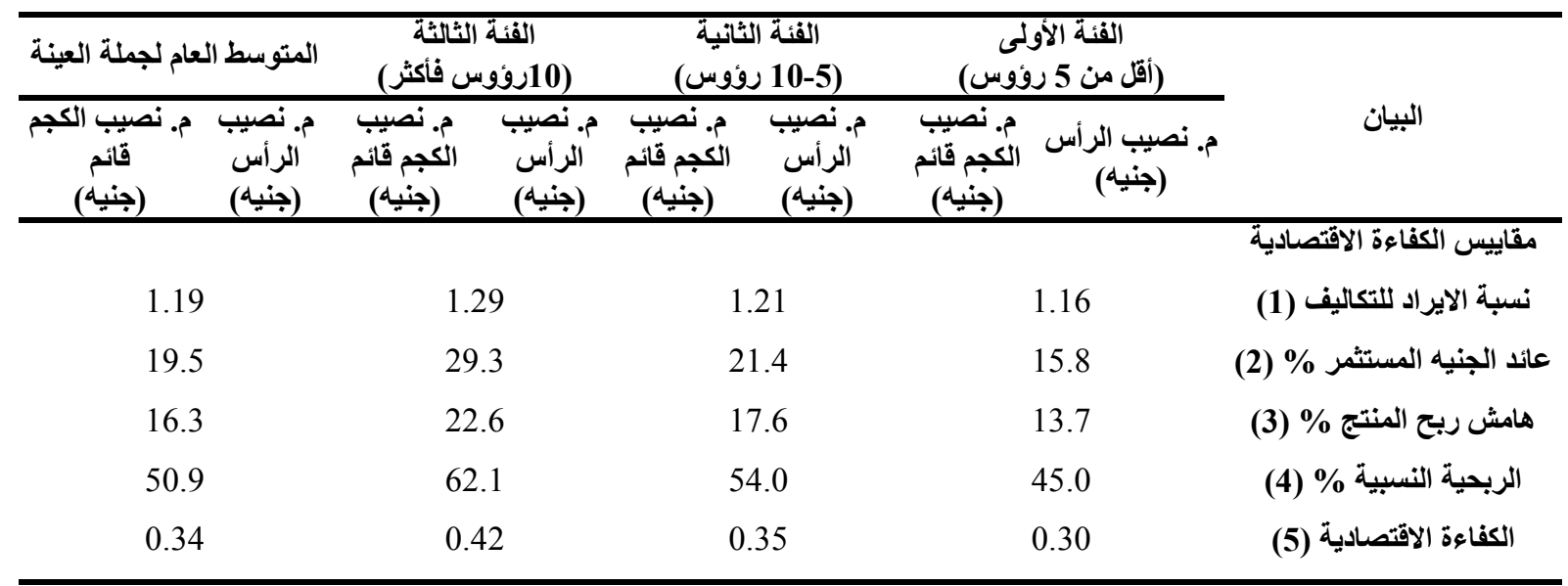

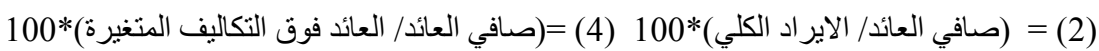

$$
\begin{aligned}
& \text { (5) = (القيمة المضافة/ التكاليف الكلية). } \\
& \text { المصدر: جُمعت وحُسبت من واقع استمارات الاستبيان الخاصة بالدر اسة الميدانية. }
\end{aligned}
$$

6- التوسع فى زراعة محاصبل الأعلاف إلى جانب

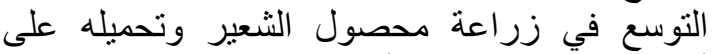

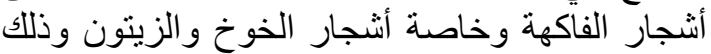
في ظل افتقار المحافظة إلى محاصيل الأعلاف خاصة محصول البرسيم.

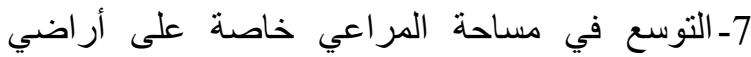
الكثبان الرملية والمناطق الجبلية داخل محافظة

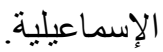
8-تعظيم الاستفادة من المخلفات الزراعية مثل مخلفات التخات الخضر والزروع البستانية و النخيل.

9ـ تكوين علائق غير تقليديه من مخلفات البيئة.

$$
\text { المراجـــ }
$$

سليمان، إبراهيم ومحمد جابر (2014). التقبيم الاقتصادي

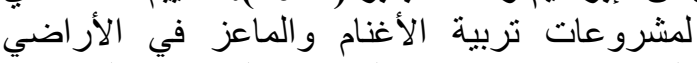

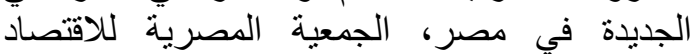

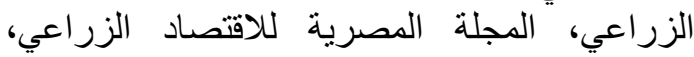
المجلد ( ؟ Y)، العدد الر ابع، ديسمبر.

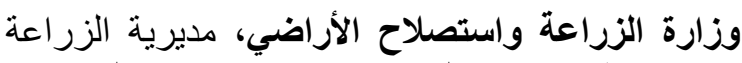
بمحافظة الإسماعلية، سجلات الإنتاج الإني، الحيواني، الزئ

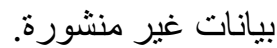

2-كما تبين أن مزارع الفئة الحيازية الثالثة قد حققت أيضا

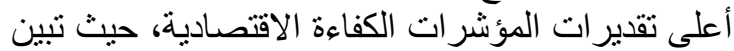

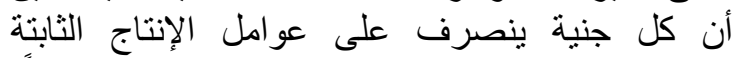

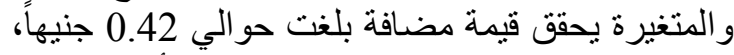
مقابل حوالي 0.30 لمز ارع الفئة الحيازية الأولي.

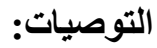
1- العمل على تتمية المراعي الطبيعية لزيادة الثروة إئادية

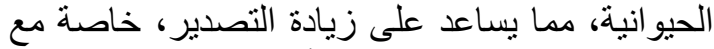

قرب محافظة الاسماعلية من الأسو اق العربية. 2-ضرورة الاهتمام بتوفير السلالات الجيدة ذات الإنتاجية العالية، وتحسين الخدمات البيطرية. 3-ضرورة قيام الدولة بتشجيع المستثمرين لاستصلاح وزراعة الأراضي القابلة للزراعة لتوفئة التوفير الأعلاف

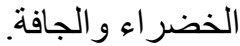

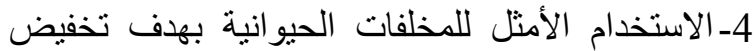
التكاليف وتحسين الدخل والحفاظ على الإلى السلالة الجيدة، ورفع كفاءة استخدام الأعلاف وقيمتها والئها الغذائية، وتفعيل دور الوحدات الإرشادية في توعية المربين لأساليب

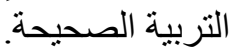
5-الاستغلال الأمثل للموارد العلفية خاصة الأعلاف الافل

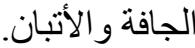




$$
\begin{aligned}
& \text { الملخص العربي } \\
& \text { دراسة اقتصادية لتسمين الأغنام في محافظة الإسماعلية } \\
& \text { عبدالفتاح نصر الله اشتيوي1، رياض إسماعيل مصطفى رضوان1، رجب محمد حفني } 1
\end{aligned}
$$

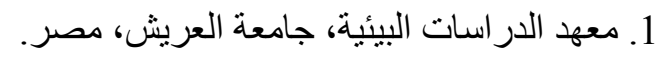

$$
\begin{aligned}
& \text { 2. قسم الاقتصاد و التنمية الريفية، كلية العلوم الزر اعية البيئية، جامعة العريش، مصنية مصر. }
\end{aligned}
$$

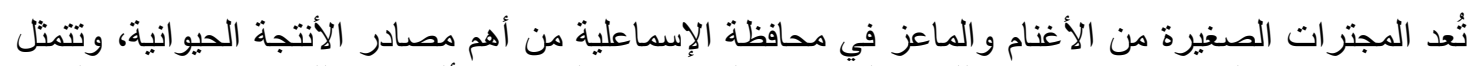

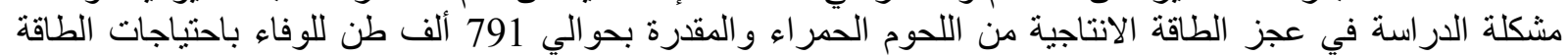

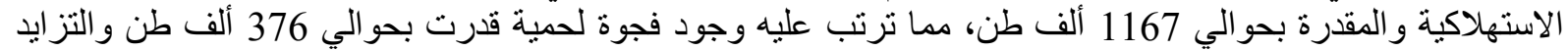

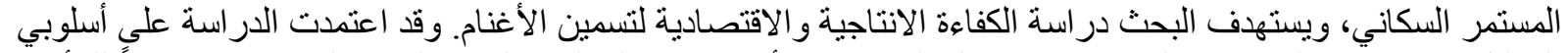

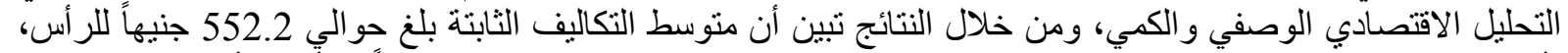

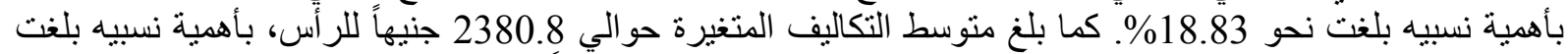

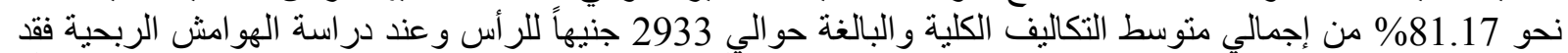

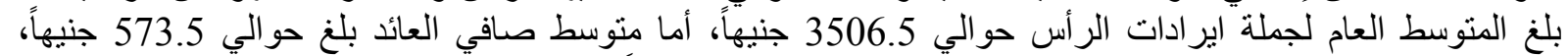

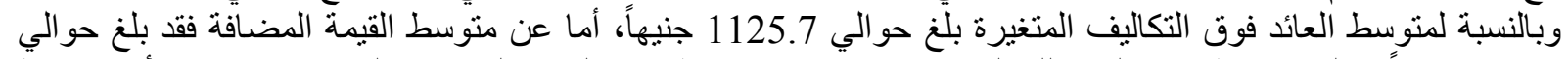

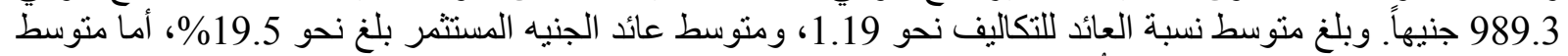

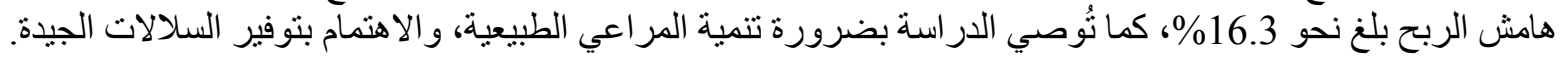
الكلمات الاسترشادية: در اسة اقتصادية، الأغنام، محافظة الإسماعيلية.

أستاذ الاقتصاد الزر اعي، كلية الزر اعة، جامعة الزقازيق، مصر. أستاذ الاقتصاد الزراعي، كلية العلوم الزراعية الزية البيئية، جامعة العريش، مصر.

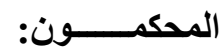

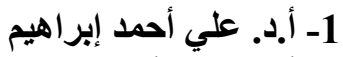

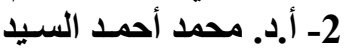


